\title{
KETERKAITAN PERSEPSI TERHADAP EKSPEKTASI ORANG TUA DENGAN KESULITAN DALAM MENGAMBIL KEPUTUSAN KARIER PADA MAHASISWA TINGKAT AKHIR
}

\author{
Azizah Fathiyah Din dan Whisnu Yudiana \\ Fakultas Psikologi Universitas Padjadjaran \\ Jl. Raya Bandung Sumedang Km 21, Kabupaten Sumedang, Jawa Barat, 45363 \\ E-mail: azizahfdin@gmail.com
}

\begin{abstract}
ABSTRAK
Jenjang mahasiswa merupakan tahap pengambilan keputusan karier yang berkaitan dengan dunia kerja. Namun, ditemukan bahwa mahasiswa tingkat akhir mengalami kesulitan dalam memutuskan kariernya. Penelitian ini bertujuan untuk menelusuri keterkaitan antara persepsi terhadap ekspektasi orang tua dengan kesulitan dalam mengambil keputusan karier pada mahasiswa tingkat akhir. Penelitian menggunakan pendekatan non-eksperimental yaitu korelasional dan data dikumpulkan menggunakan kuesioner. Teknik pengambilan sampel yang digunakan adalah simple random sampling. Penelitian dilakukan terhadap 103 mahasiswa tingkat akhir. Alat ukur yang digunakan adalah Living up to Parental Expectation Inventory dan Career Decision Making Difficulties Questionnaire. Hasil penelitian menunjukkan adanya hubungan negatif antara keduanya, di mana semakin negatif seseorang memersepsikan ekspektasi orang tuanya, maka akan semakin tinggi dia merasa kesulitan dalam mengambil keputusan karier $(\mathrm{r}=-0.28, \mathrm{p}<0.05)$. Penelitian ini menunjukan pentingnya komunikasi antara mahasiswa tingkat akhir dan orang tua.
\end{abstract}

Kata kunci: persepsi terhadap ekspektasi orang tua; keputusan karier; kesulitan dalam mengambil keputusan karier mahasiswa; mahasiswa tingkat akhir

\section{CORRELATION BETWEEN PERCEPTION OF PARENTAL EXPECTATION AND CAREER DECISION MAKING DIFFICULTIES IN FINAL YEAR COLLEGER}

\begin{abstract}
In general, college students are in the transition phase, which is a phase of career decision-making that is closely related to the world of work. However, it was found that final-year college students had difficulty in making career decisions. This study examined the correlation between perception of parental expectation and career decision-making difficulties in final-year college students. The study used a non-experimental approach, which specifically was correlational, with data collection using a questionnaire. The sampling technique was simple random sampling. The subjects of this study were 103 final-year students. Measuring instruments used are Parental Expectation Inventory and Career Decision Making Difficulties Questionnaire. The results showed a significant positive correlation between the two variables, which means that the higher the final year college students perceived their parental expectation if compared to their performance, the higher the difficulty they experience in making career decisions $(\mathrm{r}=0.28, \mathrm{p}<0.05)$. This finding emphasizes the importance of communication between final-year college students and their parents regarding their perceptions.
\end{abstract}

Keyword: perception of parental expectation; career decision making; career decision making difficulties; college student; final year student 


\section{PENDAHULUAN}

Manusia mengalami berbagai tahapan perkembangan semasa hidupnya, salah satunya adalah perkembangan karier. Menurut Chudzikowski (2012), karier adalah pengalaman bekerja individu dalam kurun waktu tertentu yang berhubungan dengan posisi pada ruang sosial seperti organisasi, atau lapangan pekerjaan. Karier terbentuk karena adanya interaksi antara individu dengan lingkungan, peran, dan kejadian yang terjadi di dalam hidupnya (Sharf, 2016).

Individu berumur 18-25 yang berada pada tahap emerging adulthood (Arnett, 2010) umumnya sedang duduk di bangku perguruan tinggi. Pada fase ini mahasiswa melakukan transisi nilai yang berkaitan dengan sekolah pada nilai yang berkaitan dengan dunia kerja sebagai pekerja (Kuron et al., 2015). Pada tahap ini, individu mulai menentukan kariernya yang berkaitan dengan pekerjaan, melakukan eksplorasi pada bidangbidang pekerjaan yang cocok, pengambilan keputusan, dan meningkatkan kemampuan yang dibutuhkan (Fouad et al., 2016)

Dalam mengambil keputusan karier, individu terpengaruh oleh faktor keluarga (Slaten \& Baskin, 2014), ekplorasi karier, dan lingkungan (Xu et al., 2014). Di antara faktor-faktor tersebut, orang tua adalah faktor yang paling berperan dalam keputusan karier seseorang. Menurut Workman (2015), orang tua mengemban peran yang cukup sentral dalam mengembangkan aspirasi karier dan membina anaknya dalam mengeksplorasi perjalanan pendidikan dan kariernya. Menurut Smollar dan Youniss (1989), orang tua tetap menjadi pengaruh yang besar dalam hidup meskipun mahasiswa sedang berada dalam proses menuju hidup lebih mandiri. Mahasiswa masih memiliki attachment yang kuat dengan orang tuanya. Mahasiswa menghormati orang tuanya, bekerja untuk persetujuan mereka, mencoba memenuhi harapan mereka, dan merasakan adanya kewajiban sebagai bagian dari keluarga. Mahasiswa melihat orang tua sebagai figur otoritas yang berhak untuk memberikan batasan dan ekspektasi terhadap perilaku mereka (Smollar \& Youniss, 1989).

Fenomena ini diperkuat ketika seseorang berada di negara-negara kolektivis seperti Malaysia, India, Taiwan, dan Indonesia, di mana pengaruh orang tua dalam kehidupan seseorang dikatakan cukup besar (Hughes, 2011). Dalam budaya kolektivis terdapat jarak kekuasaan (power distance) yang besar dalam keluarga. Tidak hanya dilihat sebagai role model dan fasilitator, tetapi juga orang tua juga mengharapkan agar anaknya patuh. Orang tua menginginkan keterlibatan terhadap keyakinan diri anaknya serta keputusan yang dibuatnya. Mengabaikan keinginan atau harapan orang tua saat membuat keputusan penting, seperti keputusan karier, dapat menjadi hal yang kontradiktif dalam diri individu (Hardin et al., 2001). Dibandingkan di negaranegara individualis seperti Amerika Serikat, Australia, dan Kanada, individu di negara kolektif memersepsikan bahwa pengaruh orang tua cukup besar pada pemilihan dan aspirasi kariernya. Oleh sebab itu, kebanyakan individu berusaha untuk menyesuaikan minat kariernya dengan persetujuan orang tua (Leong et al., 2010).

Meskipun beberapa orang berpegang teguh pada pilihan kariernya sendiri, kebanyakan orang merasa nyaman apabila karier yang dipilihnya sejalan dengan orang tua (Sawitri, 2019). Secara umum, ekspektasi orang tua didefinisikan sebagai keyakinan dan penilaian orang tua yang terkait dengan pencapaian masa depan anaknya baik yang tergambar dalam nilai akademis, kelanjutan studi, dan lainnya (Ma et al., 2018). Orang tua dapat membujuk anaknya untuk mengikuti kemauannya dengan menanamkan ekspektasi dan aspirasinya sendiri melalui keterlibatan, pemantauan, disiplin dan dukungan yang diberikannya (Sasikala \& Karunanidhi, 2011).

Persepsi terhadap ekspektasi orang tua adalah persepsi terhadap harapan/keinginan orang tuanya terkait kedewasaan pribadi, pencapaian akademis/pemilihan karier, dan isu berpacaran (Wang \& Heppner, 2002). Menurut Fukuoka (2017), individu memersepsikan ekspektasi orang tua sebagai ideal self image. Hal ini dapat memunculkan persepsi negatif atau persepsi positif terhadap ekspektasi orang tuanya. Persepsi terhadap ekspektasi orang tua yang positif menunjukkan bahwa individu merasa dirinya dekat dengan ideal self-nya. Individu merasa mampu memenuhi ekspektasi tersebut, sehingga dapat menjadikan ekspektasi itu sebagai motivasi (Chung, 2015), merasa bahagia karena akan diterima orang tuanya (Fukuoka, 2017), dan cenderung untuk melakukan perencanaan dan pencarian dalam memilih kariernya (Sawitri et al., 2014).

Ketika individu memersepsikan ekspektasi orang tuanya secara negatif, ia merasa tidak dapat memenuhi ekspektasi tersebut. Individu berpotensi mengalami hambatan dalam perkembangan dan pemilihan kariernya (Leung et al., 2011). Perbedaan antara actual self dan ideal self yang dibangun berdasarkan interaksi 
dengan orang tua akan menimbulkan hambatan secara emosional, hingga depresi (Ma et al., 2018). Individu dapat merasa tidak diterima oleh orang tuanya apabila tidak memenuhi ekspektasi mereka.

Ketidakmampuan memenuhi ekspektasi orang tua tersebut membuat seseorang merasa gagal karena mereka tidak mencapai desirable level tertentu (Fukuoka, 2017). Konflik psikologis yang muncul karena adanya konflik antara actual self, dan ideal self serta ought self dapat menghambat seseorang dalam mengambil keputusan (Higgins, 1987). Salah satu keputusan yang akan sulit untuk dibuat olehnya adalah keputusan karier (Gati \& Levin, 2014).

Kesulitan pengambilan keputusan karier dapat terjadi karena tiga faktor besar, yaitu lack of information, lack of readiness, dan inconsistent information. Faktor yang pertama adalah kurangnya akses dan penggunaan informasi (lack of information) yang terdiri dari beberapa subfaktor yaitu kurangnya informasi mengenai dirinya sendiri (lack of information about the self), kurangnya informasi terkait proses pembuatan keputusan karier (lack of information about the decision making process), kurangnya informasi mengenai bagaimana cara memperoleh informasi (lack of information about ways of obtaining information), dan kurangnya informasi mengenai pekerjaan (lack of information about occupations). Faktor yang kedua adalah kurangnya kesiapan dan keterlibatan untuk membuat keputusan karier (lack of readiness), yang terdiri dari beberapa subfaktor yaitu kurangnya motivasi (lack of motivation), adanya rasa ragu ketika membuat suatu keputusan (general indecisiveness), dan disfungsi keyakinan atau pemikiran mengenai karier (dysfunctional beliefs). Faktor yang terakhir adalah adanya informasi yang tidak konsisten atau kongruen antar satu sama lain (inconsistent information) yang dibagi menjadi tiga kategori spesifik yaitu adanya informasi yang kurang dapat dipercaya (unreliable information), konflik internal (internal conflict), dan konflik eksternal (external conflict). Gati et al. (1996) mengemukakan bahwa seseorang dapat menemukan kesulitan dalam membuat keputusan karier sebelum dan selama proses pembuatan keputusan karier berlangsung. Kurangnya kognitif atau afektif dapat menjadi salah satu sumber kesulitan penentuan keputusan karier. Keraguan seseorang dapat dihasilkan dari satu atau lebih kesulitan, dan setiap kesulitan individu dapat dihasilkan dari satu atau beberapa kategori.

Persepsi individu terhadap ekspektasi orang tuanya dapat berhubungan dengan kesulitan dalam mengambil keputusan karier ketika ia memandang tinggi ekspektasi orang tuanya, dan dapat menimbulkan stres apabila ia tidak mampu memenuhinya. Adanya stressor ini dapat membuat seseorang berpikiran negatif yang akhirnya dapat membuatnya kurang siap (lack of readiness) dalam memutuskan karier apa yang ia akan jalani (Bullock-Yowell et al., 2011). Ketika ada kesenjangan antara ekspektasi orang tua dan performanya, mereka memiliki affective distress (seperti perasaan marah, depresi, dan anxiety) yang lebih besar (Agliata \& Renk, 2008). Perasaan negatif ini mempersulit integrasikan dan asimilasikan skema pada kognitif seseorang terkait dirinya dan informasi karier yang ia punya serta mengklarifikasi preferensi pribadinya (Gati \& Tal, 2007; Saunders et al., 2000). Hal tersebut dapat menghambat eksplorasi karier dan pilihan yang ada (Kelly \& Shin, 2008) Hal ini dapat membuat mahasiswa tidak memiliki informasi yang memadai (lack of information) untuk membuat keputusan karier.

Kesulitan yang dirasakan dari ekspektasi orang tua juga dapat tergambar dalam kategori kesulitan inconsistent information. Kategori kesulitan ini menunjukkan bahwa informasi yang tidak konsisten atau kongruen dapat mempersulit seseorang dalam membuat keputusan karier. Dalam kategori tersebut, external conflict, internal conflict, dan unreliable information memiliki hubungan dengan persepsi terhadap ekspektasi orang tua (Gati et al., 1996).

Setelah meninjau penelitian terdahulu dan menemukan kesulitan pengambilan keputusan karier pada mahasiswa tingkat akhir (Prayoga, 2016), tujuan dari penelitian ini adalah untuk menelusuri apakah terdapat keterkaitan antara persepsi terhadap ekspektasi orang tua dan kesulitan dalam mengambil keputusan karier pada mahasiswa tingkat akhir serta bagaimana arah hubungan di antara kedua variabel tersebut.

\section{METODE}

Penelitian ini menggunakan pendekatan kuantitatif non-eksperimental dengan jenis penelitian korelasional. Teknik sampling yang digunakan adalah probability sampling, tepatnya simple random sampling. Kriteria sampel merupakan mahasiswa tingkat akhir S1 yang berusia 18-21 tahun.

Variabel persepsi terhadap ekspektasi orang tua diukur dengan menggunakan Living up to Parental Expectation Inventory yang disusun oleh Wang \& Heppner (2002) yang diterjemahkan ke dalam bahasa 
Indonesia dengan forward-backward translation. Alat ukur ini mengukur penilaian individu terhadap tinggi rendahnya ekspektasi orang tua jika dibandingkan dengan performanya. Skor living up to parental expectation didapatkan dari selisih skor perceived self performance dan perceived parental expectation. Jika skor living up to parental expectation bernilai negatif, persepsi ekspektasi orang tuanya akan lebih tinggi daripada kemampuan dirinya sehingga ia tidak dapat memenuhinya. Jika skor living up to parental expectation bernilai positif, persepsi ekspektasi orang tuanya akan lebih rendah daripada kemampuan dirinya sehingga ia mampu memenuhinya. LPEI terdiri dari 32 item dengan skala likert yang terbagi menjadi 1-6, dari 'tidak sama sekali' sampai 'sangat besar'. Nilai reliabilitas alat ukur ini didapatkan sebesar 0.871 , reliabilitas bagian perceived parental expectation sebesar 0.914, dan perceived self performance sebesar 0.860 .

Variabel kesulitan dalam mengambil keputusan karier diukur menggunakan Career Decision Making Difficulties Questionnaire yang disusun oleh Gati et al. (1996) yang sudah diterjemahkan ke dalam bahasa Indonesia oleh Jayanti (2018). Alat ukur ini mengukur kesulitan yang dirasakan individu ketika membuat keputusan dalam tiga kategori, yakni lack of readiness, lack of information, dan inconsistent information. CDDQ terdiri dari 34 item, dengan skala likert yang terbagi menjadi 1-9, dari 'sangat tidak sesuai' sampai 'sangat sesuai'. CDDQ memiliki nilai reliabilitas sebesar 0.903 .

Pengambilan data dilakukan secara klasikal. Responden dihubungi terlebih dahulu, kemudian diberikan penjelasan singkat mengenai penelitian, termasuk manfaat mengikuti penelitian dan resikonya. Setelah diberikan waktu untuk memutuskan, responden kemudian diberikan lembar informed consent yang boleh dikembalikan jika tidak bersedia. Pengisian informed consent disaksikan oleh peneliti dan asisten peneliti. Setelah itu responden yang bersedia diberikan lembar kuesioner. Data yang didapat diolah menggunakan pearson product moment untuk menelaah korelasi antara keduanya, dan digunakan pengolahan statistika deskriptif (persentase, mean, median) untuk data demografis. Keseluruhan metode dalam penelitian ini telah ditinjau dan disetujui oleh Komisi Etik Penelitian Universitas Padjadjaran Bandung dengan Nomor: 1284/UN6.KEP/EC/2019.

\section{HASIL DAN PEMBAHASAN}

Terdapat 103 responden dalam penelitian ini. Mayoritas mahasiswa tingkat akhir yang mengikuti penelitian ini adalah perempuan, yaitu sebanyak $87.4 \%$ dari total responden, sementara $12.6 \%$ sisanya adalah laki-laki. Usia responden beragam dari 19-21 tahun $(\mathrm{M}=20.7, \mathrm{SD}=0.47)$.

Tabel 1. Data Demografi Responden Penelitian

\begin{tabular}{llcc}
\hline & Kategori & Jumlah & Persentase \\
\hline Jenis Kelamin & Laki-Laki & 13 & $12.6 \%$ \\
& Perempuan & 90 & $87.4 \%$ \\
Usia & 19-21 Tahun & $\begin{array}{c}M=20.7 \\
(\mathrm{SD}=0.47)\end{array}$ \\
\hline
\end{tabular}

Pada tabel 2, skor rata-rata LPEI yang negatif $(M=-0.43, \mathrm{SD}=0.7)$ menunjukkan bahwa mahasiswa tingkat akhir cenderung memersepsikan ekspektasi orang tuanya secara negatif karena mereka merasa ekspektasi orang tuanya $(M=4.57, \mathrm{SD}=0.7)$ lebih tinggi daripada performanya $(M=4.14, \mathrm{SD}=0.63)$. Kemudian, ditemukan pula bahwa kesulitan paling tinggi yang dialami mahasiswa tingkat akhir dalam mengambil keputusan karier adalah lack of readiness.

Skor rata-rata perceived parental expectation mahasiswa tingkat akhir juga dapat dikatakan cukup tinggi. Hal ini relevan dengan penelitian yang dilakukan oleh Smollar dan Youniss (1989), di mana kemandirian mahasiswa tidak membuat pengaruh orang tua menjadi lebih kecil dalam hidupnya. Hal ini juga diperkuat oleh budaya Indonesia yang kolektivis, di mana anak lebih sering diberikan harapan tertentu oleh orang tua terkait tanggung jawab dan perannya (Sawitri et al., 2014).

Hasil uji korelasi pada tabel 2 menunjukkan adanya hubungan negatif yang signifikan antara persepsi terhadap ekspektasi orang tua dengan kesulitan dalam mengambil keputusan karier, dengan korelasi rendah ( $\mathrm{r}$ 
$=-0.28, \mathrm{p}<0.05)$. Semakin negatif persepsi mahasiswa tingkat akhir mengenai ekspektasi orang tuanya, maka semakin tinggi kesulitannya dalam mengambil keputusan karier. Korelasi paling kuat antara persepsi terhadap ekspektasi orang tua dengan kategori kesulitan dalam mengambil keputusan karier terdapat pada kategori inconsistent information yaitu sebesar $-0.27(\mathrm{p}<0.05)$, kemudian lack of readiness dengan koefisien korelasi sebesar -0.22 ( $\mathrm{p}=0.026)$, dan lack of information dengan koefisien korelasi sebesar -0.21 ( $\mathrm{p}=0.037)$. Terdapat hubungan positif dengan kategori rendah antara perceived parental expectation dengan kategori kesulitan inconsistent information $(\mathrm{r}=0.33, \mathrm{p}<0.05)$.

Mahasiswa tingkat akhir yang menilai persepsi terhadap ekspektasi orang tuanya jauh lebih tinggi daripada performanya dapat mengalami perasaan/emosi negatif yang lebih besar (Wang \& Heppner, 2002). Hal ini dapat memengaruhinya dalam membuat keputusan. Ketika mahasiswa merasa performanya lebih baik daripada ekspektasi orang tuanya, ia dapat memiliki kapasitas yang lebih besar untuk menghadapi permasalahan dalam memilih karier (Leung, 2011) dan memiliki self worth yang tinggi (Agliata \& Renk, 2008).

Dengan adanya perhatian dari lingkungan luar yang melebihi apa yang dibutuhkan oleh seseorang, ia dapat melihatnya sebagai tekanan (Fadhillah \& Yudiana, 2020). Oleh karena itu, ketika mahasiswa mempersepsikan ekspektasi orang tuanya dengan negatif karena ia menilai performa dirinya lebih rendah dibandingkan performa yang diharapkan oleh orangtuanya, ia cenderung memiliki self worth yang lebih rendah (Agliata \& Renk, 2008). Hasil ini sejalan pula dengan penelitian Trinidad (2019) yang menunjukkan bahwa adanya ekspektasi orang tua yang unrealistic untuk dicapai dapat menurunkan performa mahasiswa secara keseluruhan.

Mahasiswa tingkat akhir dengan persepsi ekspektasi orang tua yang tinggi melihat hal tersebut sebagai stressor (Ma et al., 2018), dan melaporkan affective distress (seperti perasaan marah, depresi, dan anxiety) yang lebih besar (Agliata \& Renk, 2008). Stressor ini dapat membuat seseorang berpikiran negatif yang membuatnya kurang siap (lack of readiness) dalam memutuskan karier apa yang ia akan jalani (Bullock-Yowell et al., 2011).

Perasaan negatif ini dapat mempersulit integrasi dan asimilasi skema terkait dirinya dan informasi karier yang serta mengklarifikasi preferensi pribadinya (Gati \& Levin, 2014). Hal tersebut dapat menghambat seseorang dalam mengeksplorasi karier dan pilihan yang ada untuk dirinya. Akibatnya, ia tidak punya informasi yang cukup untuk membuat keputusan karier.

Tabel 2. Hasil Uji Korelasi antara Persepsi Terhadap Ekspektasi Orang Tua dengan Kesulitan Dalam Mengambil Keputusan Karier

\begin{tabular}{lcccccccc}
\hline & $M(\mathrm{SD})$ & PPE & PSP & LPE & CDMD & LOR & LOI & II \\
\hline PPE & $4.57(0.7)$ & 1 & $0.4^{*}$ & $-0.61^{*}$ & 0.18 & 0.01 & 0.052 & $0.33^{*}$ \\
PSP & $4.14(0.63)$ & & 1 & $0.48^{*}$ & -0.13 & -0.15 & -0.18 & 0.045 \\
LPE & $-0.43(0.73)$ & & & 1 & $-0.28^{*}$ & $-0.22^{*}$ & $-0.21^{*}$ & $-0.27^{*}$ \\
CDMD & $4.4 .(0.98)$ & & & & 1 & $0.67^{*}$ & $0.9^{*}$ & $0.82^{*}$ \\
LOR & $4.75(0.8)$ & & & & & 1 & $0.44^{*}$ & $0.42^{*}$ \\
LOI & $4.44(1.5)$ & & & & & & 1 & $0.58^{*}$ \\
II & $3.97(1.16)$ & & & & & & & 1 \\
\hline
\end{tabular}

${ }^{*}$ Korelasi signifikan $(p$-value $<0.05)$

$\mathrm{CDMD}=$ Career Decision Making Difficulties; LOR = Lack of Readiness; $\mathrm{LOI}=$ Lack of Information; $\mathrm{II}=$ Inconsistent Information; PPE = Perceived Parental Expectation; PSP = Perceived Self Performance; LPE = Living up to Parental Expectation.

Leung et al. (2011) mengemukakan bahwa konflik antara orang tua-anak dalam pemilihan karier dapat menjadi sumber utama permasalahan information inconsistency terutama pada negara kolektivis, salah satunya Indonesia. Negara kolektivis memberikan penekanan pada tanggung jawab seseorang terhadap keluarga dan orang tuanya. Individu diharapkan untuk mematuhi dan membuat bahagia orang tuanya. Hal ini menjelaskan hasil signifikansi korelasi antara perceived parental expectation dengan kategori kesulitan inconsistent information. Baik ketika ekspektasi orang tua dinilai dapat dipenuhi atau tidak, keduanya dapat membuat seseorang mengalami kesulitan dalam kategori ini. 
Ditemukan beberapa limitasi yang dapat digunakan sebagai acuan untuk pertimbangan penelitian selanjutnya, yaitu belum digalinya faktor lain yang dapat memengaruhi/berhubungan dengan dinamika dua variabel pada mahasiswa tingkat akhir. Oleh karena itu, saran untuk penelitian selanjutnya adalah menelaah moderasi faktor lain seperti pola asuh dan kedekatan dengan orang tua.

\section{SIMPULAN}

Berdasarkan uraian analisis uji hipotesis di atas, dapat diambil kesimpulan bahwa terdapat hubungan negatif antara persepsi terhadap ekspektasi orang tua dengan kesulitan dalam mengambil keputusan karier. Persepsi negatif terhadap ekspektasi dari orang tuanya dapat mempengaruhi kesulitan dalam mengambil keputusan karier. Oleh karena itu, mahasiswa tingkat akhir diharapkan untuk meningkatkan self awareness dan self understanding agar dapat memahami kebutuhan, emosi, pikiran, dan stres yang dirasakannya terkait persepsi terhadap ekspektasi orang tuanya yang berkaitan dengan proses pengambilan keputusan karier. Kesadaran ini dapat membuat seseorang memiliki pemahaman yang menyeluruh tentang dirinya, dan hal tersebut dapat mempermudah seseorang untuk mengomunikasikan ketidakseimbangan antara ekspektasi yang dirasakannya dengan kemampuannya. Mahasiswa tingkat akhir perlu mengomunikasikan persepsinya terhadap ekspektasi orang tua dan bagaimana ia menilai performanya kepada orang tua agar terjadi negosiasi, kompromi, dan kooperasi antara kedua pihak. Dengan penelitian ini, mahasiswa tingkat akhir perlu didukung untuk menyelesaikan konflik yang terjadi karena persepsinya terhadap ekspektasi orang tua agar tidak menyulitkannya dalam membuat keputusan karier.

\section{DAFTAR PUSTAKA}

Agliata, A. K., \& Renk, K. (2008). College students' adjustment: The role of parent-college student expectation discrepancies and communication reciprocity. Journal of Youth and Adolescence, 37, (8), 967-982. doi: https://doi.org/ 10.1007/s10964-007-9200-8

Arnett, J. J. (2010). Emerging adulthood (s). Bridging cultural and developmental approaches to psychology: New syntheses in theory, research, and policy, 255-275.

Bullock-Yowell, E., Andrews, L., \& Buzzetta, M. E. (2011). Explaining career decision-making self-efficacy: Personality, cognitions, and cultural mistrust. The career development quarterly, 59, (5), 400-411. doi: https://doi.org/10.1002/j.2161-0045.2011.tb00967.x

Chudzikowski, K. (2012). Career transitions and career success in the 'new' career era. Journal of Vocational Behavior, 81(2), 298-306. doi: https://doi.org/10.1016/j.jvb.2011.10.005

Chung, R. U. (2015). Parental expectations for Asian American men who entered college early: Influences on their academic, career, and interpersonal decision-making (Doctoral dissertation).

Fadhillah, S. H., \& Yudiana, W. (2020). Kesulitan pengambilan keputusan karier pada siswa di daerah rural: Bagaimana peran dukungan sosial?. Persona: Jurnal Psikologi Indonesia, 9, (2), 229-248.

Fukuoka, Y. (2017). Effects of Trust in Parents, Expectations from Parents, and Perception of Parents' Expectations on University Students' Achievement Motivation. Kawasaki journal of medical welfare, 22, (2), 61-76. doi: https://doi.org/10.15112/00014328

Fouad, N. A., Ghosh, A., Chang, W. H., Figueiredo, C., \& Bachhuber, T. (2016). Career exploration among college students. Journal of College Student Development, 57, (4), 460-464.

Gati, I., Krausz, M., \& Osipow, S. H. (1996). A taxonomy of difficulties in career decision making. Journal of counseling psychology, 43, (4), 510. doi: https://doi.org/10.1037/0022-0167.43.4.510

Gati, I., \& Levin, N. (2014). Counseling for career decision-making difficulties: Measures and methods. The Career Development Quarterly, 62, (2), 98-113. doi: https://doi.org/ 10.1002/j.2161-0045.2014 00073.x

Higgins, E. T. (1987). Self-discrepancy: a theory relating self and affect. Psychological review, 94, (3), 319.

Hughes, C. (2011). The influence of self-concept, parenting style and individualism-collectivism on career maturity in Australia and Thailand. International Journal for Educational and Vocational Guidance, 11, (3), 197-210. doi: https://doi.org/10.1007/s10775-011-9208-1

Jayanti, I.S. (2018). Pengembangan Instrumen Career Decision Making Difficulties Questionnaire (CDDQ). (Tesis: Tidak dipublikasikan). Universitas Padjadjaran. 
Kuron, L. K. J., Lyons, S. T., Schweitzer, L., \& Ng, E. S. W. (2015). Millennials' work values: Differences across the school to work transition. Personnel Review, 44, 991-1009. https://doi.org/10.1108/PR-012014-0024

Leong, F. T., Hardin, E. E., \& Gupta, A. (2011). Self in vocational psychology: A cultural formulation approach. doi: https://doi.org/1037/12348-012

Leung, S. A., Hou, Z. J., Gati, I., \& Li, X. (2011). Effects of parental expectations and cultural-values orientation on career decision-making difficulties of Chinese university students. Journal of Vocational Behavior, 78, (1), 11-20. doi: http://doi.org/10.1016/j.jvb.2010.08.004

Ma, Y., Siu, A., \& Tse, W. S. (2018). The role of high parental expectations in adolescents' academic performance and depression in Hong Kong. Journal of family issues, 39, (9), 2505-2522. doi: https://doi.org/10.1177/0192513X18755194

Oztemel, K. (2013). An Investigation of Career Indecision Level of High School Students: Relationships with Personal Indecisiveness and Anxiety. Online Journal of Counseling \& Education, 2, (3).

Prayoga, J. S. (2016). Studi Deskriptif Mengenai Career Decision Making Difficulties pada Mahasiswa Angkatan 2011 Universitas "X" di Kota Bandung. Undergraduate thesis, Universitas Kristen Maranatha.

Sasikala, S., \& Karunanidhi, S. (2011). Development and validation of perception of parental expectations inventory. Journal of Indian Academy of Applied Psychology, 37, (1), 114-124.

Saunders, D. E., Peterson, G. W., Sampson Jr, J. P., \& Reardon, R. C. (2000). Relation of depression and dysfunctional career thinking to career indecision. Journal of Vocational Behavior, 56, (2), 288-298.

Sawitri, D. R. (2019). Career Congruence with Parents from the Perspective of Gender. 1st Annual International Conference on Social Sciences and Humanities (AICOSH 2019) (pp. 244-248). Atlantis Press.

Sawitri, D. R., Creed, P. A., \& Zimmer-Gembeck, M. J. (2014). Parental influences and adolescent career behaviours in a collectivist cultural setting. International Journal for Educational and Vocational Guidance, 14(2), 161-180.

Sharf, R. S. (2016). Applying career development theory to counseling. Cengange Learning.

Slaten C. D., Baskin W. B. (2014). Examining the impact of peer and family belongingness on the career decision-making difficulties of young adults: A path analytic approach. Journal of Career Assessment, 22, 59-74. doi: https://doi.org/10.1177/1069072713487857

Smollar, J., \& Youniss, J. (1989). Transformations in adolescents' perceptions of parents. International Journal of Behavioral Development, 12(1), 71-84. doi: https://doi.org/10.1177/016502548901200104

Trinidad, J. E. (2019). Understanding when parental aspirations negatively affect student outcomes: The case of aspiration-expectation inconsistency. Studies in Educational Evaluation, 60, 179-188. doi: https://doi.org/ 10.1016/j.stueduc.2019.01.004

Wang, L. F., \& Heppner, P. P. (2002). Assessing the impact of parental expectations and psychological distress on Taiwanese college students. The Counseling Psychologist, 30(4), 582-608. doi: https://doi.org/ $10.1177 / 00100002030004006$

Workman, J. L. (2015). Parental influence on exploratory students' college choice, major, and career decision making. College Student Journal, 49(1), 23-30.

Xu, H., Hou, Z. J., \& Tracey, T. J. (2014). Relation of environmental and selfcareer exploration with career decision-making difficulties in Chinese students. Journal of Career Assessment, 22 (4), 654-665.

Yamamoto, Y., \& Holloway, S. D. (2010). Parental expectations and children's academic performance in sociocultural context. Educational Psychology Review, 22(3), 189-214. doi: https://doi.org/10.1007/s10648-010-9121-Z

Zhou, N., Cao, H., Nie, Y., Li, X., Yu, S., Liang, Y., ... \& Fang, X. (2019). Career-Related Parental Processes and Career Adaptability and Ambivalence Among Chinese Adolescents: A Person-Centered Approach. Journal of Research on Adolescence. doi: https://doi.org/10.1111/jora.12520 